\title{
The technical (re-)examination of Vermeer's Girl with a Pearl Earring
}

\author{
Abbie Vandivere*
}

What makes Johannes Vermeer's Girl with a Pearl Earring (c. 1665, Mauritshuis, Fig. 1) so intriguing? In 1881, the Girl was purchased at auction for two guilders (plus a thirty cent commission) [1]. Now visitors from all over the world come to the Mauritshuis to experience this painting. Seeing the Girl in person, you become captivated by her presence, her gaze, the way she opens her mouth as if to speak, and how her earring shines against the shadow of her neck. Visitors often have questions: Was she a real person? Why did Vermeer paint her? Although we might not be able to fully answer these questions using scientific means, we can discover how Vermeer brought the Girl to life.

In 2018, Girl with a Pearl Earring underwent a technical examination in front of the museum public at the Mauritshuis. The Girl in the Spotlight project involved an international team of scientists and conservators. The overall goal was to find out more about the materials, techniques that Vermeer used to create this masterpiece, and to document the current condition of the painting since its last treatment in 1994 [2-4]. The research questions that guided the 2018 technical examination were:

What steps did Vermeer take to create the painting?

What can we find out about layers beneath the surface?

Which materials did Vermeer use and where did they come from?

Which techniques did Vermeer use to create subtle optical effects?

What did the painting look like originally, and how has it changed?

*Correspondence: a.vandivere@mauritshuis.nl

Conservation Department, Mauritshuis, Plein 29, 2511 CS The Hague, The Netherlands
What is the chemical and physical condition of the painting?

Over the course of two weeks, Girl with a Pearl Earring underwent a complete 'body scan' with the most advanced non-invasive imaging techniques, including: technical photography, reflectance and molecular fluorescence imaging spectroscopy (RIS, FIS), fibre optic reflectance spectroscopy (FORS), multispectral infrared reflectography (MS-IRR), macroscopic X-ray fluorescence (MA-XRF), macroscopic X-ray powder diffraction (MA-XRPD), multi-scale optical coherence tomography (MS-OCT), 3D scanning, 3D digital microscopy, and computer-assisted thread-level canvas analysis (Fig. 2). These revealed the chemical composition of the paint layers; visualised the underlayers, surface topography and differences in opacity; and provided a visual image of the entire painting at $4.4 \mu \mathrm{m} /$ pixel. The research team also investigated the layers of the painting by analysing microsamples using: scanning electron microscopy-energy dispersive X-ray analysis (SEM-EDX), focused ion beam-scanning transmission electron microscopy (FIBSTEM), Fourier transform infrared-attenuated total reflectance spectroscopy (FTIR-ATR), ultra-high-performance liquid chromatography (UHPLC), gas chromatography mass spectrometry (GCMS), synchrotron radiation $\mathrm{X}$-ray techniques ( $\mu$-XRPD/ $\mu$-XANES), and lead isotope analysis. The macro-imaging and micro-analyses complemented each other to provide a full picture of the materials and techniques that Vermeer used to create Girl with a Pearl Earring.

\section{About the project}

The research project The Girl in the Spotlight is a Mauritshuis initiative and involves a team of internationally recognised specialists associated with the Netherlands Institute 


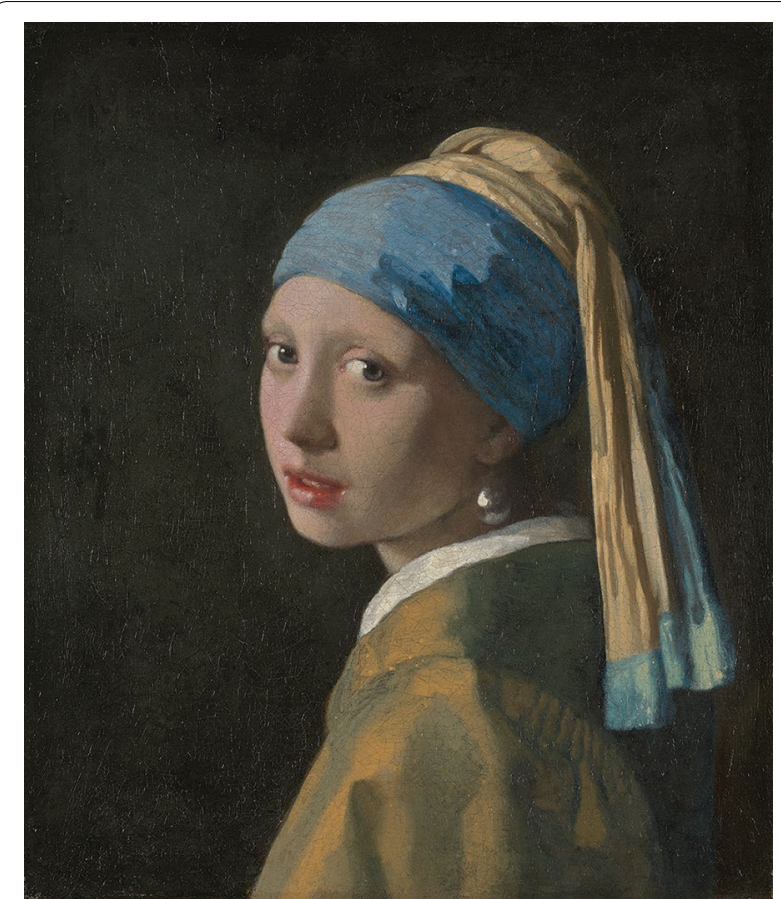

Fig. 1 Johannes Vermeer, Girl with a Pearl Earring, c. 1665. MH670, Mauritshuis, The Hague. Visible light photograph: René Gerritsen Art \& Research Photography, reused with permission

for Conservation + Art + Science $+(\mathrm{NICAS})$, and scientists from the University of Antwerp, Belgium, and the National Gallery of Art, Washington DC, USA (Fig. 3). This project was made possible with support from the Johan Maurits Compagnie Foundation.

\section{NICAS partners}

- Mauritshuis: Abbie Vandivere, Annelies van Loon (Rijksmuseum/Mauritshuis)

- Rijksmuseum: Robert van Langh, Annelies van Loon, Alessa Gambardella (Rijksmuseum/AkzoNobel), Victor Gonzalez (Rijksmuseum/TU Delft), Robert Erdmann (Rijksmuseum/UvA)

- Delft University of Technology (TU Delft): Joris Dik, Tom Callewaert, Victor Gonzalez, Mathijs van Hengstum, Willemijn Elkhuizen, Tessa Essers, Yu Song, Jeroen Kalkman

- Cultural Heritage Agency of the Netherlands (RCE): Klaas Jan van den Berg, Bauke Zeilstra, Art Ness Proaño Gaibor, Suzan de Groot, Henk van Keulen

- University of Amsterdam (UvA): Robert Erdmann.

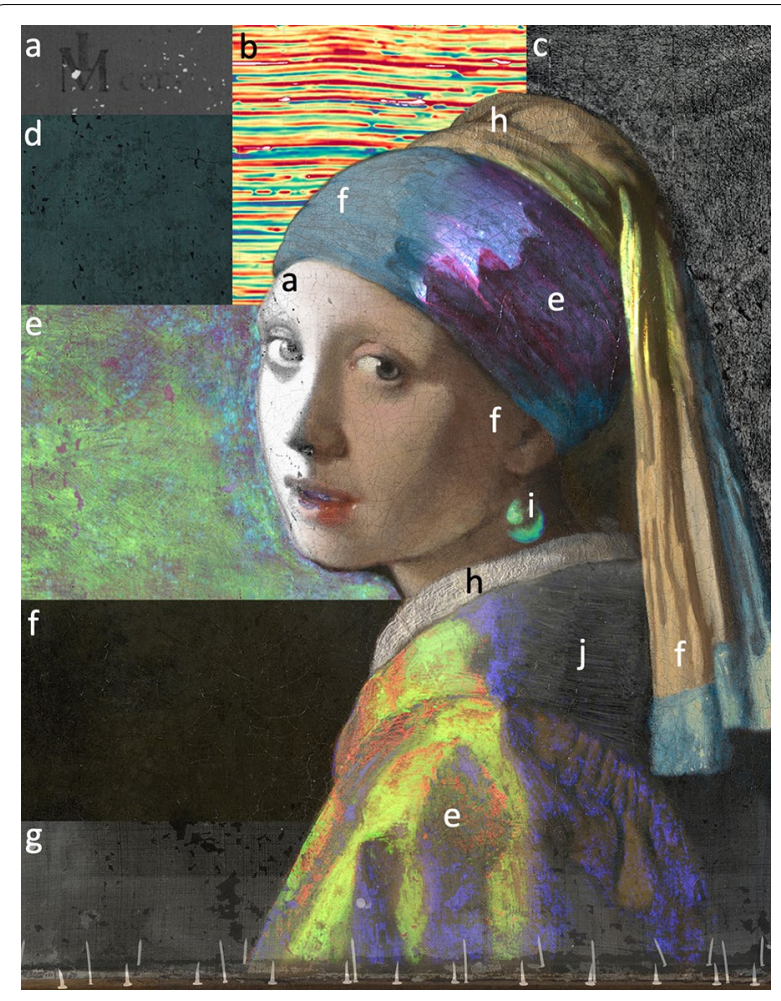

Fig. 2 Composite image of Girl with a Pearl Earring from images made during the Girl in the Spotlight project: a MA-XRF, b computer-assisted thread-level canvas analysis, c MS-OCT, d UV-induced fluorescence photograph, e RIS false-colour reflectance image, $\mathbf{f}$ polarised light photograph, $\mathbf{g}$ X-radiograph, h Raking light photograph, i 3D scanning based on fringe-encoded stereo imaging, $\mathbf{j}$ MS-IRR. Imaging techniques not included: MA-XRPD, 3D microphotography. Composite image: Sylvain Fleur and the Girl in the Spotlight team, used with permission

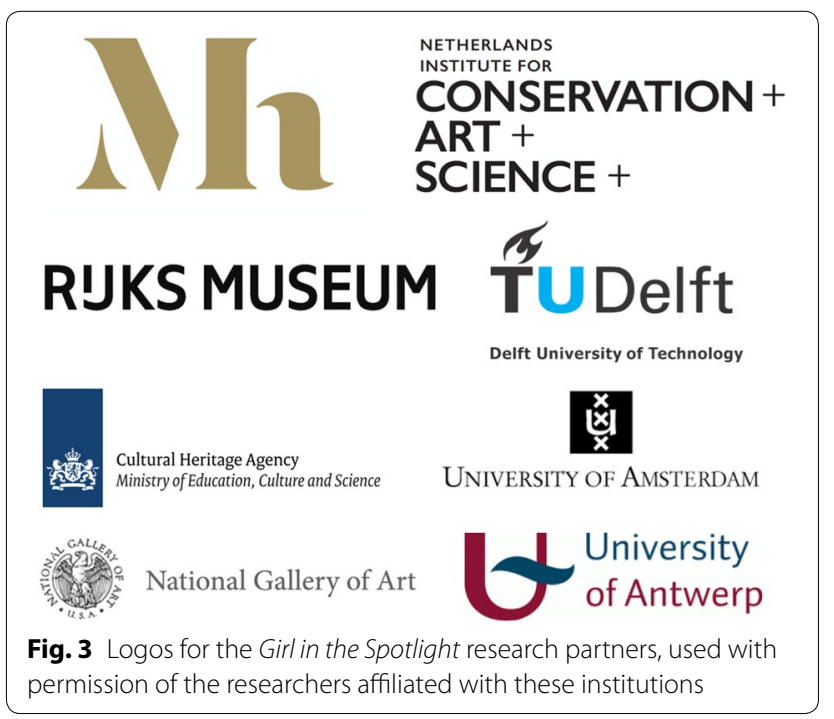




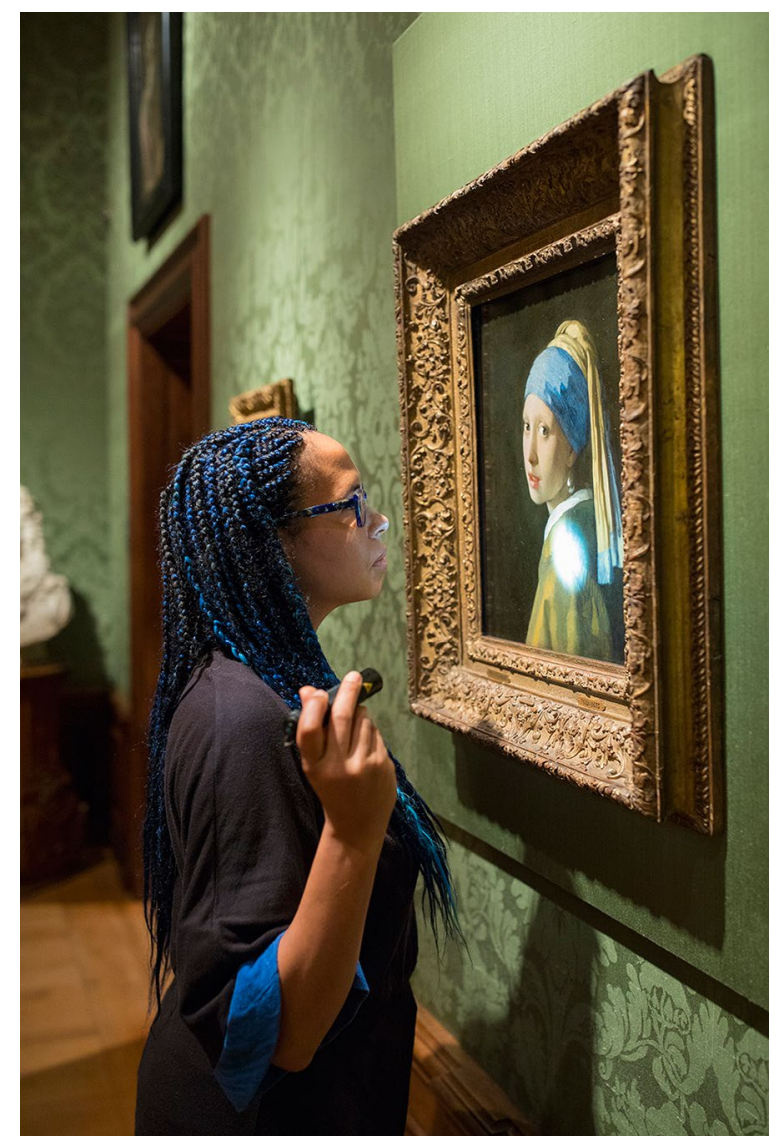

Fig. 4 Abbie Vandivere looking at Girl with a Pearl Earring in the Mauritshuis. Photograph: Ivo Hoekstra, Mauritshuis, used with permission

\section{Other partners}

- National Gallery of Art, Washington DC: John Delaney, Kathryn A. Dooley

- University of Antwerp: Koen Janssens, Geert van der Snickt, Steven De Meyer, Frederik Vanmeert, Rani Vertongen

- Shell Technology Centre Amsterdam (STCA): Bob van Wingerden, Ralph Haswell

- Hirox Europe: Jyfel: Emilien Leonhardt, Vincent Sabatier/Hirox Japan: Mr. Takeuchi and Mr. Nakajima

- Statens Museum for Kunst/CATS, Copenhagen: Jørgen Wadum

- René Gerritsen Kunst \& Onderzoeksfotografie: René Gerritsen, Jaap Hoogerdijk, assistance with photographic set-up: Robert Erdmann

- Maastricht University: Ron Heeren, Anne Bruinen, Hans Duimel
- Vrije Universiteit Amsterdam/NICAS project: Multiisotopic analysis of early modern art (MITEEMA). Paolo D'Imporzano, Gareth R. Davies

- European Synchrotron Radiation Facility (ESRF), Grenoble, France-ID21 beamline: Marine Cotte, Wout de Nolf

- PETRA-III, Deutsches Elektronen-Synchrotron (DESY), Hamburg, Germany-P06 beamline: Matthias Alfeld, Jan Garrevoet

- 3D print displayed during Girl in the Spotlight examination: Océ: A Canon Company

- Project team (Mauritshuis): Hedwig Wösten, Edwin Buijsen, Abbie Vandivere, Sandra Verdel, Boy van den Hoorn, Marty Plas, Julie Vegter, Lea van der Vinde.

\section{Suggested reading order}

The results of the Girl in the Spotlight project have culminated in a special collection of articles in Heritage Science. Each article focuses on a specific area of the painting, part of the layer structure or examination technique. Although each can stand its own, they are intended to be read in the following order:

'From 'Vermeer Illuminated' to 'The Girl in the Spotlight': Approaches and methodologies for the scientific (re-)examination of Vermeer's Girl with a Pearl Earring' describes the (conservation) history of the painting, reviews the technical examination that took place in 1994, and introduces the technologies used in the 2018 research project [5].

'Revealing the painterly technique beneath the surface of Vermeer's Girl with a Pearl Earring using macro- and microscale imaging' provides a glimpse into the canvas, ground, and the initial steps that Vermeer took to create the Girl [6].

'Mapping the pigment distribution of Vermeer's Girl with a Pearl Earring' shows how a combination of RIS, FIS and MA-XRF was used to locate and identify the materials in different areas of the painting [7].

'Comparison of three 3D imaging techniques for paintings, as applied to Vermeer's Girl with a Pearl Earring' describes how MS-OCT, 3D scanning and 3D digital microscopy were used to map the surface topography of the painting, and the advantages and limitations of each method [8].

'Imaging secondary reaction products at the surface of Vermeer's Girl with a Pearl Earring by means of in situ macro X-ray powder diffraction scanning' explains how MA-XRPD identified some of Vermeer's original painting materials and evidence of degradation processes that have occurred over time [9]. 
'Beauty is skin deep: The skin tones of Vermeer's Girl with a Pearl Earring' focuses on the materials and layer stratigraphy of the Girl's face, and how Vermeer created the soft contours and flawless transition from light to shadow [10].

'Out of the blue: Vermeer's use of ultramarine in Girl with a Pearl Earring' describes the materials and techniques used to paint the blue headscarf, and how changes over time have affected its appearance [11].

'Fading into the background: the dark space surrounding Vermeer's Girl with a Pearl Earring' explains the materials and stratigraphy of the background, and reveals how Vermeer's original concept for the background has been affected by degradation [12].

'The Girl in the Spotlight: Vermeer at work, his materials and techniques in Girl with a Pearl Earring' is a review of the preceding chapters written for a (technical) art-historical audience, and answers the research questions posed at the outset of the project [13].

\section{Acknowledgements}

The Girl in the Spotlight team would like to thank the peer reviewers who provided valuable feedback on all of the articles: Silvia Centeno, The Metropolitan Museum of Art; Maria Perla Colombini, University of Pisa; Marco Leona, The Metropolitan Museum of Art; Douglas MacLennan, Getty Conservation Institute; Dorothy Mahon, The Metropolitan Museum of Art; Francesca Modugno, University of Pisa; Bronwyn Ormsby, Tate; Josefina Pérez-Arantegui, University of Zaragoza; Emeline Simone Pouyet, Northwestern University; Mikkel Scharff, The Royal Danish Academy of Fine Arts (KADK); Kim Pilkjær Simonsen, The Royal Danish Academy of Fine Arts (KADK); Diego Tamburini, The British Museum/Freer Gallery of Art \& Arthur M. Sackler Gallery; Joyce Townsend, Tate; and anonymous reviewers. We would also like to thank: Richard Brereton, Editor-in-Chief of Heritage Science; Matthew Smyllie, Senior Journal Development Editor, Chemistry \& Materials Science, Springer Nature.

\section{Authors' contributions}

AV wrote the main body of the text and was the Head Researcher for the Girl in the Spotlight project. The author read and approved the final manuscript.

\section{Author's information}

Dr. Abbie Vandivere, Guest Editor (Fig. 4). Dr. Abbie Vandivere is the Head Researcher of the Girl in the Spotlight project. She graduated with a BA from Princeton University (U.S.A.), a Pg.Dip.Cons. from the Courtauld Institute of Art (U.K.), and a Ph.D. from the University of Amsterdam (the Netherlands). Her research interests include 15th-17th-century Dutch painting technique, and making reconstructions using historically appropriate materials. She is a paintings conservator at the Mauritshuis in The Hague, the Netherlands. She coordinates and teaches in the Technical Art History MA programme within the department of Conservation and Restoration at the University of Amsterdam.

\section{Funding}

The Netherlands Institute for Conservation + Art + Science + funded the participation of the NICAS partners in the project, including use of analytical equipment and the time devoted to the project by scientists from the RCE, TU Delft, UvA and the Rijksmuseum. The Girl in the Spotlight project was made possible with support from the Johan Maurits Compagnie Foundation.

\section{Availability of data and materials}

The datasets used and/or analysed during the current study are available from the corresponding author on reasonable request.

\section{Competing interests}

The author declares that they have no competing interests.

Received: 3 March 2020 Accepted: 3 March 2020

Published online: 11 March 2020

\section{References}

1. Broos B, van Suchtelen A. Portraits in the Mauritshuis 1430-1790. Zwolle: Waanders Publishers; 2004

2. Groen K, van der Werf I, van den Berg K, Boon J. Scientific examination of Vermeer's "Girl with a Pearl Earring". In: Gaskell I, Jonker M, editors. Vermeer studies: studies in the history of art 55. New Haven: National Gallery of Art, Washington; 1998. p. 168-83.

3. Wadum J, Hoppenbrouwers R, Struick and der Loeff L. Vermeer illuminated. Conservation, restoration and research. Wormer: VK Publishing/ Inmerc; 1994.

4. Wadum J, Vermeer's CNJ 'Girl with a Pearl Earring' De- \& Re-Restored. In: Restauration, Dé-Restauration, Re-Restauration..., Preprints of ARAAFU's 4th international symposiumm, Paris; 1995 Oct, p. 5-7.

5. Vandivere A, Wadum J, van den Berg KJ, van Loon A. From 'Vermeer illuminated' to 'The Girl in the Spotlight': approaches and methodologies for the scientific (re-)examination of Vermeer's Girl with a Pearl Earring. Herit Sci. 2019;7:66. https://doi.org/10.1186/s40494-019-0307-5.

6. Vandivere A, van Loon A, Dooley KA, Haswell R, Erdmann RG, Leonhardt E, Delaney JK. Revealing the painterly technique beneath the surface of Vermeer's Girl with a Pearl Earring using macro- and microscale imaging Herit Sci. 2019;7:64. https://doi.org/10.1186/s40494-019-0308-4.

7. Delaney JK, Dooley KA, Van Loon A, Vandivere A. Mapping the pigment distribution of Vermeer's Girl with a Pearl Earring. Herit Sci. 2020;8:4. https ://doi.org/10.1186/s40494-019-0348-9.

8. Elkhuizen WS, Callewaert TWJ, Leonhardt E, Vandivere A, Song Y, Pont SC, Geraedts JMP, Dik J. Comparison of three 3D imaging techniques for paintings, as applied to Vermeer's Girl with a Pearl Earring. Herit Sci. 2019;7:89. https://doi.org/10.1186/s40494-019-0331-5.

9. De Meyer S, Vanmeert F, Vertongen R, van Loon A, Gonzalez V, Dik J, Van der Snickt G, Vandivere A, Janssens K. Imaging secondary reaction products at the surface of Vermeer's Girl with a Pearl Earring by means of in situ macro X-ray powder diffraction scanning. Her Sci. 2019;7:67. https://doi. org/10.1186/s40494-019-0309-3.

10. Van Loon A, Vandivere A, Delaney J, Dooley K, De Meyer S, Vanmeert F, Janssens K, Gonzalez V, Leonhardt E, Haswell R, de Groot S, Proaño Gaibor AN, D'Imporzano P, Davies GR. Beauty is skin deep: the skin tones of Vermeer's Girl with a Pearl Earring. Herit Sci. 2019;7:102. https://doi. org/10.1186/s40494-019-0344-0.

11. Van Loon A, Gambardella A, Gonzalez V, Cotte M, de NolfW, Keune K, Leonhardt E, Proaño Gaibor AN, Vandivere A. Out of the blue: Vermeer's use of ultramarine in Girl with a Pearl Earring. Herit Sci. 2020;8:19. https:// doi.org/10.1186/s40494-020-00364-5.

12. Vandivere $A$, van Loon A, Callewaert T, Haswell R, Proaño Gaibor AN, van Keulen $\mathrm{H}$, Leonhardt E, Dik J. Fading into the background: the dark space surrounding Vermeer's Girl with a Pearl Earring. Herit Sci. 2019;7:69. https ://doi.org/10.1186/s40494-019-0311-9.

13. Vandivere A, Wadum J, Leonhardt E. The Girl in the Spotlight: Vermeer at work, his materials and techniques in Girl with a Pearl Earring. Herit Sci. 2020;8:20. https://doi.org/10.1186/s40494-020-0359-6.

\section{Publisher's Note}

Springer Nature remains neutral with regard to jurisdictional claims in published maps and institutional affiliations. 